\title{
HYDROLOGICAL AND ECOLOGICAL EFFECT OF CAOHAI WATERSHED REGULATION PROJECT BASED ON SWAT MODEL
}

\author{
ZHOU, C. W. - YU, L. F.* - ZHOU, Y.-YAN, L. B. \\ College of Life Sciences, Guizhou University, Guiyang, Guizhou, China \\ (e-mails: C.W. Zhou-changwei.1981@163.com; Y.Zhou-812305593@qq.com; L. B. Yan- \\ link_yan@126.com) \\ *Corresponding author \\ e-mail: gdyulifei@163.com \\ (Received $15^{\text {th }}$ Sep 2018; accepted $12^{\text {th }}$ Nov 2018)
}

\begin{abstract}
Based on the satellite image of Caohai river watershed in 2017, the land use types of Caohai river watershed were determined by field investigation, which were divided into six categories: farmland, forest land, grassland, water area, construction land and unused land. Based on SWAT model, the nonpoint source pollution of four regulation projects in Caohai watershed was simulated, and the runoff, sediment, nitrogen and phosphorus of non-point source pollution were analyzed in detail. The results showed that the non-point source pollution in Caohai watershed was light under the four regulation projects. The non-point source pollution is the least under the mode of conversion from farmland to forest land, grassland, water area, construction land and unused land.
\end{abstract}

Keywords: Caohai watershed, regulation project, non-point source pollution, SWAT model

\section{Introduction}

The serious water pollution, soil erosion and water resource waste in China make the freshwater resources unable to be fully utilized and aggravate the contradiction between the development of human society and natural resources. Water pollution is divided into point source pollution and non-point source pollution, in which point source pollution has a fixed discharge port (Zang and Gao, 2016), while non-point source pollution is difficult to be treated because of its wide range, complex composition and high uncertainty (Sakaguchia et al., 2014). Relying only on the prevention and control of point source pollution cannot fundamentally solve the water environment problems at the river watershed scale (Wu et al., 2012). The effectiveness of the treatment of point source pollution is often offset by the increase of agricultural non-point source pollution discharge, so that water pollution cannot be well controlled (Luo et al., 2014). In some river watersheds, non-point source pollution has exceeded point source pollution and become the main cause of water environment quality decline (Li et al., 2013; Luo et al., 2014). Therefore, more and more countries are concerned about the role of non-point source pollution in the process of water quality deterioration ( $\mathrm{Li}$ et al., 2013).

The STANFORD model was introduced. This is the first hydrological model for watershed planning. It has relatively low data requirements and can easily calculate the pollution load (Luo et al., 2014) at the exit of the watershed. Scholars are applying it to the watershed of their own country (Dechmi et al., 2012; Strauch and Volk, 2013), with the rapid development of computer technology and the rapid development of remote sensing technology and geographic information system, the function of non-point source model is increasingly powerful. The most representative and the most promising distributed model with the widest application is SWAT model. The model can discretize 
the watershed in many ways, reflect the spatial heterogeneity and hydrophysical process of the watershed (Yuan et al., 2015; Guo et al., 2014), and can better simulate the impact of human activities on the hydrological cycle of the watershed (Zhao et al., 2016; Li et al., 2017).

Fan et al. (2015) described the sources and harms of agricultural non-point source pollution, and introduced the progress of domestic agricultural non-point source pollution prevention measures from the aspects of pollution prevention measures of livestock and poultry breeding, technologies needed for rural sewage treatment, technologies related to control of chemical fertilizers and pesticides, and treatment technologies of rural household waste. In this study, multiple hydrological response unit partitioning method, the minimum threshold means that if land use, soil use or slope is less than this value, then will not be taken into account (Ficklin et al., 2009). The SWAT sensitivity analysis module, which starts with the 2005 edition, is used to determine parameters that have a significant impact on the model for subsequent calibration (Rahman et al., 2015). The sensitivity analysis of the model was performed by LH-OAH analysis method, which is the combination of LH (Latin Hypercube) sampling method and OAT, so it has the advantages of both methods (Zhang et al., 2017).

In recent years, the development of Caohai in Weining County of Guizhou province has also been developing rapidly. At the same time, the area of Caohai wetland is gradually decreasing, people want to survive, birds want to live, the degradation of Weining Caohai wetland, soil erosion is serious, biodiversity is threatened, highlighting the contradiction between protection and development. The unreasonable use of the land type structure in Caohai has led to great problems in the planning of the Caohai regulation project, which has weakened the ecological effects and reduced the biodiversity of the Caohai Lake. The study of the four regulation project in Weining Caohai watershed can not only enrich the use of SWAT model, but also provide a basis for pollution control in national nature reserves, and also provide a strong guarantee for the next step of controlling Caohai watershed. It is of great significance for the rational use of land resources and ecological environment protection in Guizhou Caohai watershed.

\section{Research method}

\section{Research area characterization}

Caohai (north latitude 264 $47^{\prime} 32^{\prime \prime}-26^{\circ} 52^{\prime} 52^{\prime \prime}$, east longitude $104^{\circ} 10^{\prime} 16^{\prime \prime}-104^{\circ} 20^{\prime} 40^{\prime \prime}$ ) is located in Weining County, western Guizhou Province, China. It is the largest plateau natural freshwater lake in Guizhou. It is also the world's top ten bird watching base. The topographical trend of the Caohai watershed is complex, with the west, south and east sides being higher, and gradually decreasing from the center of the watershed to the north, becoming the direction of the drainage of the Caohai Lake watershed. The grass sea lake watershed is surrounded by plateau melting hills, the terrain is gentle, and the ground is relatively small. From the Caohai Lake watershed, the landform is a plateau hilly watershed, and the ground is undulating (Fig. 1).

Caohai belongs to subtropical monsoon humid climate zone. It has no severe cold in winter, no severe heat in summer, large daily temperature difference and small annual temperature difference. The annual average temperature is about $10.6{ }^{\circ} \mathrm{C}$, the annual average minimum temperature is $1.7^{\circ} \mathrm{C}$, the annual average maximum temperature is 
$17.6{ }^{\circ} \mathrm{C}$, the annual average precipitation is $909 \mathrm{~mm}$, and the average relative humidity is $79 \%$. The average annual sunshine hours are $1800 \mathrm{~h}$, the frost-free period is 180 days, The rainy season is distinct from the dry season. May-October is the rainy season, the rainfall in this period is accounted for $88 \%$ of the precipitation throughout the whole year, from December to March there is only $5 \%$ of the total annual amount (Zheng et al., 2013; Xia et al., 2016).

Caohai watershed covers an area of $380 \mathrm{~km}^{2}$, the lake water area is about $45 \mathrm{~km}^{2}$, the altitude is $2173 \mathrm{~m}$, the water depth is about $2 \mathrm{~m}$, the water storage capacity reaches 140 million $\mathrm{m}^{3}$. There are 43 species and 142 genera of aquatic plants in Caohai. Caohai attracts more than 100 species of birds and more than 70 species of rare birds. Among them, the black-necked crane is the most rare migratory bird, which flies here more and more often every year to overwinter therefore, it is becoming the wintering paradise of the black-necked crane (Luo et al., 2017).

The change of water volume in Caohai affects the depth of water and determines the survival space of waterbirds. In recent years, the expansion of county towns has affected the water quality of Caohai. Therefore, it is of great significance to understand the changes of water quality and quantity in the basin for the protection of Hou Dao, represented by black-necked crane.

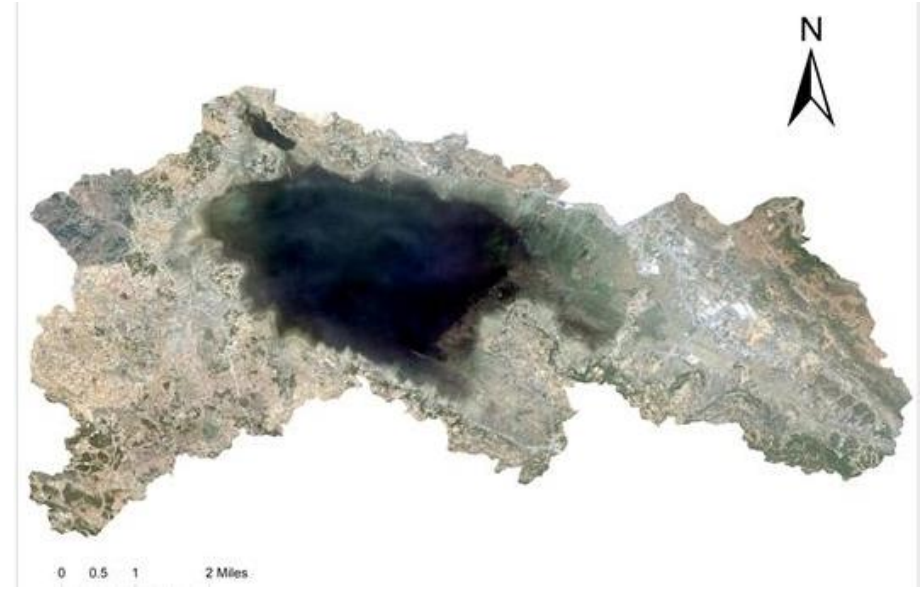

Figure 1. Topographic map of Caohai watershed

\section{Data preparation for SWAT model construction}

According to the Classification Standards for Land Use Status (GB/T21010-2017) and the actual situation of Caohai watershed, the land use types in the research area of Caohai watershed are divided into six categories. As shown in Table 1.

Table 1. Distribution characteristics of land use types in the study region

\begin{tabular}{c|c|c|c|c}
\hline Model coding & Land types & Type code & Area & Percentage of total area \\
\hline 0 & Farmland & AGRL & 5136.16 & $53 \%$ \\
1 & Forest land & FRST & 690.40 & $7 \%$ \\
2 & Grassland & RNGE & 820.80 & $8 \%$ \\
3 & Unused land & SWRN & 146.24 & $2 \%$ \\
4 & Construction land & URLD & 867.20 & $9 \%$ \\
5 & Water area & WATR & 2028.16 & $21 \%$ \\
\hline
\end{tabular}


Soil spatial distribution data from the Institute of Geography of the Chinese Academy of Sciences $(1: 100,000)$. The quality of soil data directly affects the effect of model simulation.

Because of the small scope of the Caohai Basin, there is no meteorological station in the study area, so it is difficult to obtain accurate meteorological data of the Caohai Basin. In this study, the climate change in the study area was simulated with the meteorological data from the SWAT meteorological database. Runoff, sediment and other results are generated by the model.

\section{Result and analysis}

\section{Output analysis of the Caohai sub watershed}

Typical sub watershed division

Under the regulation project of SWAT model, the outlet of Jiahaizi river watershed, Dongshan river watershed, Baima river watershed and Zhonghe river watershed are selected to simulate the output, and the map of the simulated operation of the four sub watersheds is superimposed to get Figure 2.

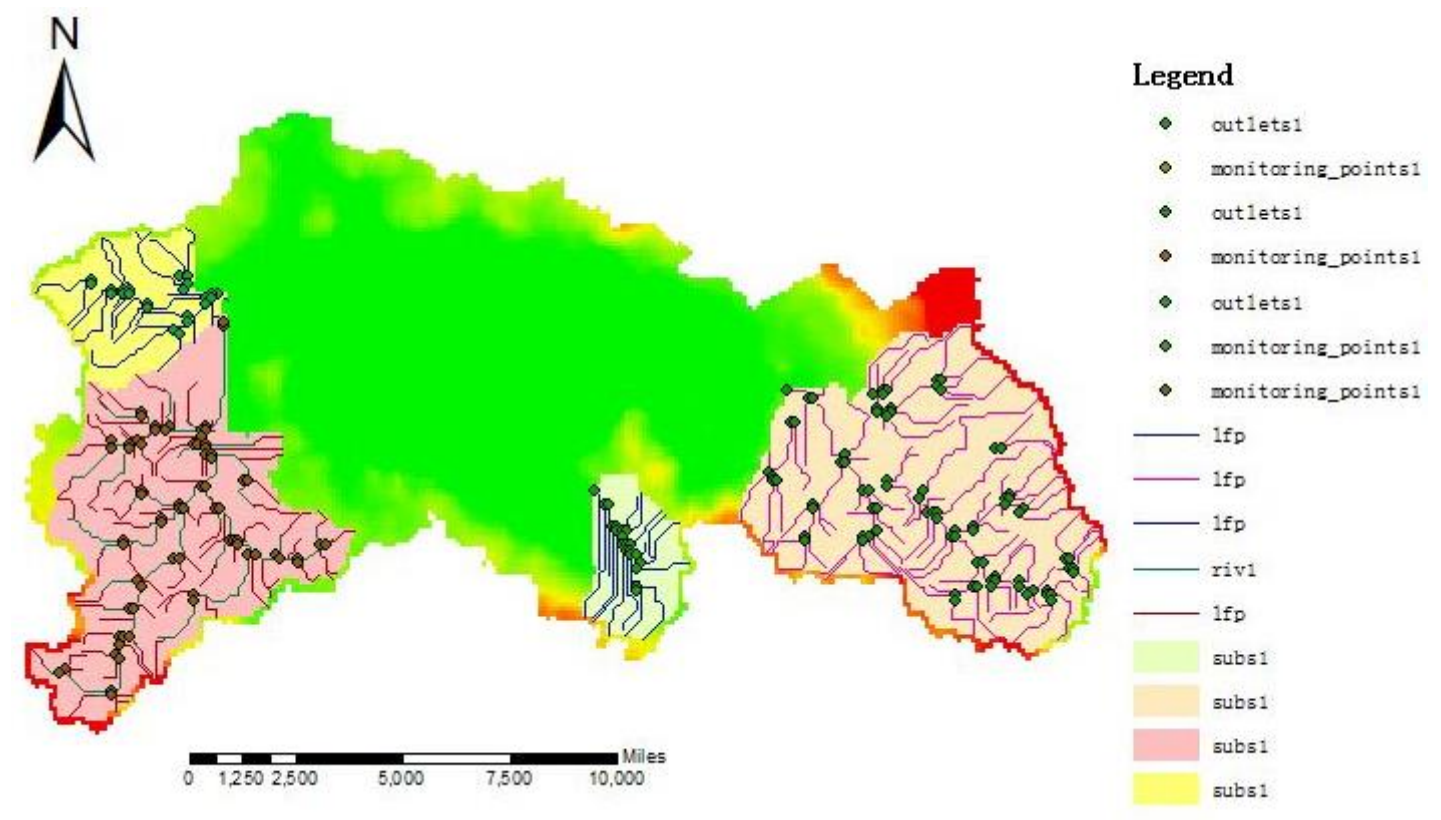

Figure 2. Distribution map of typical sub watershed in Caohai

\section{Watershed runoff analysis}

The data of rainfall, runoff, sediment and nutrients in the four river watersheds of the Jiahaizi river watershed, Dongshan river watershed, Baima river watershed and Zhonghe river watershed were analyzed to study the characteristics of pollutants in the whole river watershed, advising on the study of watersheds and the control and management of pollutants.

According to Figures 3 and 4, the total rainfall in Caohai watershed in 2017 was $1241,90 \mathrm{~mm}$, the average rainfall was $103.49 \mathrm{~mm}$, and the most rainfall was in May; 
the sum of the four watersheds was $1421.52 \mathrm{~mm}$, the average was $118.46 \mathrm{~mm}$; the sum of the sediments in the four watersheds was $82.80 \mathrm{t} / \mathrm{ha}$, with an average of $6.90 \mathrm{t} / \mathrm{ha}$.

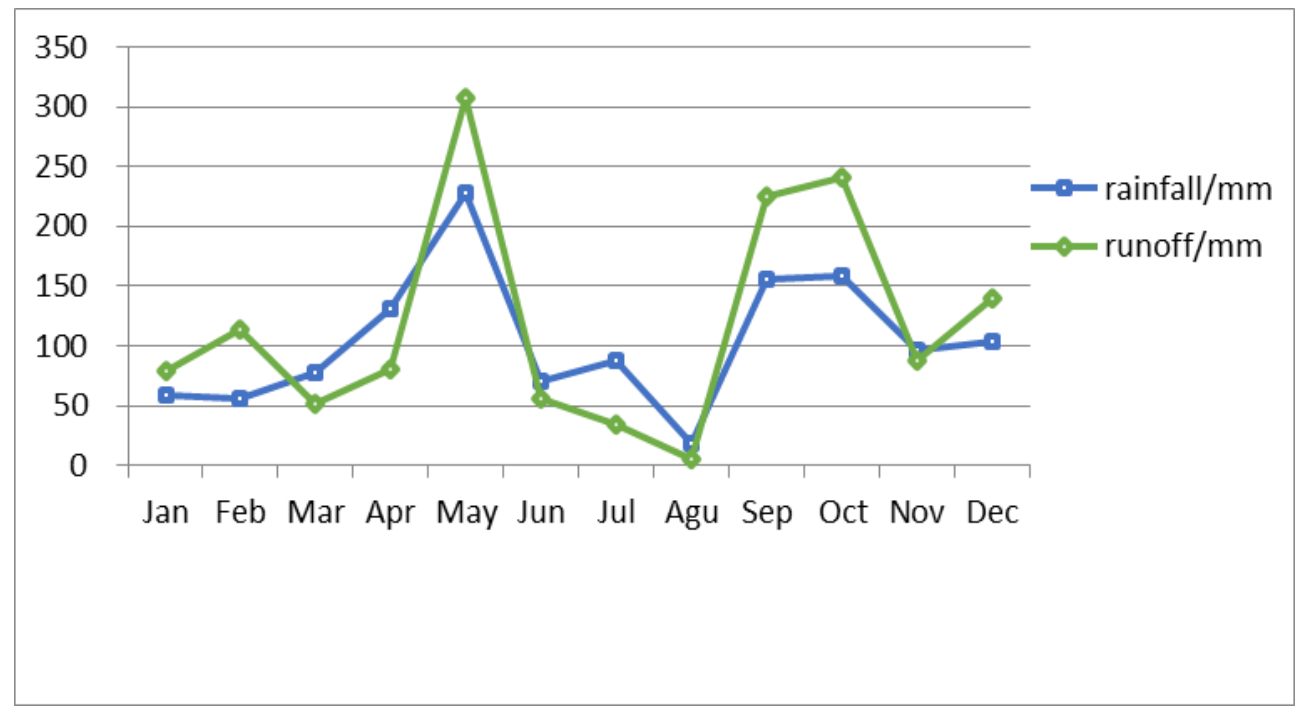

Figure 3. Comparison of monthly precipitation and monthly runoff

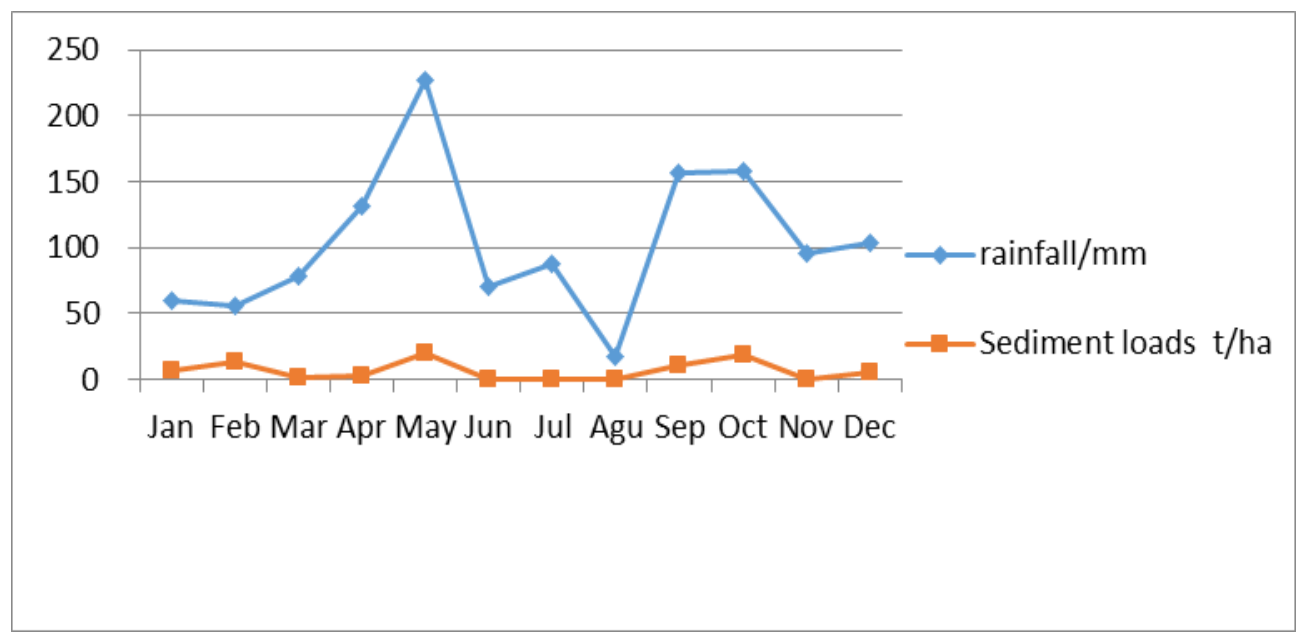

Figure 4. Comparison of monthly precipitation and monthly sediment amount

The precipitation was $227.25 \mathrm{~mm}$ in May, in the year with the most rainfall in Caohai watershed. The runoff showed an increasing trend with the increase of precipitation, which indicated that the runoff was related to rainfall, and it was proved that the runoff was related to rainfall, so the simulation reliability of the model was proved. The amount of sediment also increases with the increase of rainfall, which shows that the output of sediment is mainly concentrated in the flood season, and the output of sediment in flood season is the largest. The data also show that it is necessary to control the pollution from non-point sources. In time, we should take advantage of the periods when the output of non-point sources is the highest, such as flood season and the month when the rainfall is the highest, so as to do some preventive measures to reduce the output of non-point source more efficiently. 


\section{Analysis of typical pollutants in river watershed}

According to Table 2, it can be concluded that the total nitrogen (TN) and total phosphorus (TP) in the Jiahaizi river watershed are the least, which is $98.54 \mathrm{~kg} / \mathrm{ha}$, $13.49 \mathrm{~kg} / \mathrm{ha}$, which indicates that the chemical fertilizer application in the Jiahaizi river watershed is less, and the chemical fertilizer application in the corresponding Baima river watershed is more serious. Total nitrogen content reached $414.16 \mathrm{~kg} / \mathrm{ha}$, Total phosphorus content $52.10 \mathrm{~kg} / \mathrm{ha}$. It is also obvious that the total phosphorus content in the watershed with higher total nitrogen is also higher, indicating that there is a relationship between the nitrogen and phosphorus content in the soil. According to the situation of total nitrogen and total phosphorus in the four watersheds, it can be seen that the application of chemical fertilizer is more serious in the whole watershed, and corresponding measures should be taken to reduce the application of chemical fertilizer.

Table 2. Contents of $T N$ and $T P$ in four river watershed

\begin{tabular}{c|c|c}
\hline Sub watershed name & TN $(\mathbf{k g} / \mathbf{h a})$ & $\mathbf{T P}(\mathbf{k g} / \mathbf{h a})$ \\
\hline Jiahaizi river watershed & 98.54 & 13.49 \\
Dongshan river watershed & 226.57 & 29.06 \\
Baima river watershed & 414.16 & 52.10 \\
Zhonghe river watershed & 353.10 & 44.14 \\
\hline
\end{tabular}

TN: total nitrogen, TP: total phosphorus

\section{Simulation of the effect of four regulation project on output}

\section{Land use of four kinds of regulation project}

The comprehensive control of shelterbelt construction and greening measures have improved non-point source pollution. In order to further reduce water pollution and consolidate the comprehensive treatment effect, in response to the national water source protection policy, the implementation of "returning farmland to forests" and "returning farmland to grassland" measures The land use of the four regulation project is shown in Figure 5.

After the land use change, the forest land increased by 53\% under the mode of farmland changed into forest land, the forest land increased by $9 \%$ under the mode of building changed into forest land, the grassland increased by $53 \%$ under the mode of farmland changed into grassland, the grassland increased by $9 \%$ under the mode of building changed into grassland, and other land use types did not change.

\section{Influence on runoff under four regulation project scenarios}

Runoff is the main driving force of non-point source pollution. The change of regional runoff directly affects the change of non-point source pollution load, and runoff is the product of land use conditions. The model simulates the output of runoff and sediment under four regulation projects, as shown in Table 3. 

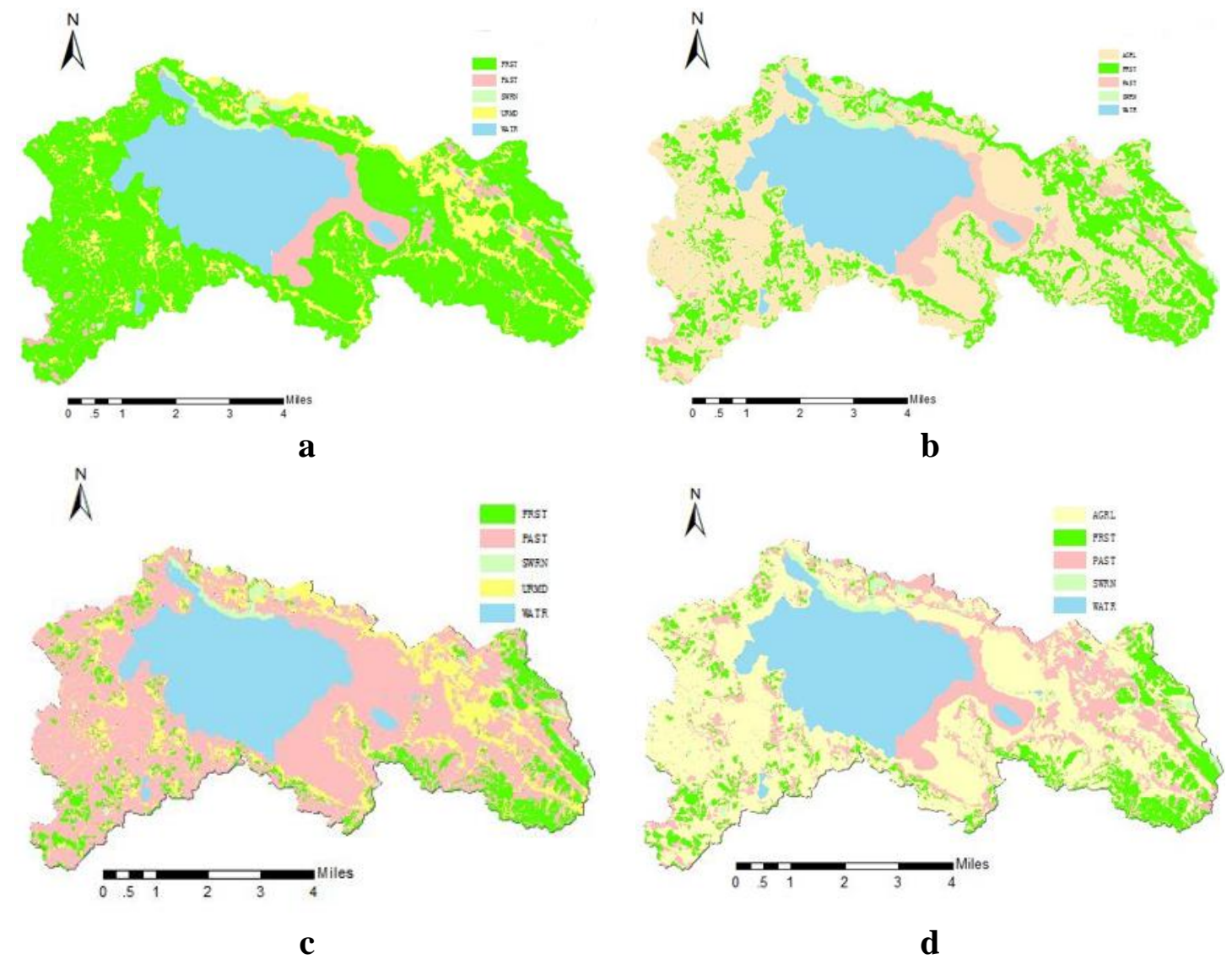

Figure 5. Four regulation modes. $\boldsymbol{a}$ Farmland changed into forestland. $\boldsymbol{b}$ Building changed into forestland. $\boldsymbol{c}$ Farmland changed into grassland. $\boldsymbol{d}$ Building changed into grassland

Table 3. Runoff and sediment quantity under regulation project mode

\begin{tabular}{c|c|c}
\hline Regulation project mode & Runoff quantity $\mathbf{~ m m}$ & Sediment quantity t/ha \\
\hline Farmland changed into forestland & 289.37 & 89.47 \\
Building changed into forestland & 301.86 & 97.13 \\
Farmland changed into grassland & 321.12 & 107.26 \\
Building changed into grassland & 295.62 & 94.31 \\
\hline
\end{tabular}

In the case of the same rainfall in 2017, the runoff and sediment volume will vary with the type of land use. When the farmland was changed into forest land mode, the runoff is $289.37 \mathrm{~mm}$, and the sediment volume is $89.47 \mathrm{~mm}$, which is $8 \%$ more than the sediment volume in 2017. When the building was changed into forest land mode, the runoff is $301.86 \mathrm{~mm}$, and the sediment volume is $97.13 \mathrm{~mm}$, which is $17.3 \%$ more than the sediment volume in 2017. When the farmland was changed into grassland mode, the runoff is $321.12 \mathrm{~mm}$, and the sediment volume is $107.26 \mathrm{~mm}$, which is $29.5 \%$ higher than the sediment volume in 2017. When the building was changed into grassland mode, the runoff is $295.62 \mathrm{~mm}$, and the sediment volume is $94.31 \mathrm{~mm}$, which is $13.9 \%$ higher than the sediment volume in 2017. At the same time, it can be seen that the runoff of farmland converted to grassland is the largest, and the amount of sediment increases with the increase of runoff. 


\section{Influence on four regulation project on typical pollutants}

The average annual load of nitrogen and phosphorus can be obtained by simulating the non-point source pollution under the four regulation project, of which the annual load of TN and TP in the base period is the average load of TN and TP in 2017. The total nitrogen and phosphorus loads were obtained by model simulation of the four regulation project, as shown in Table 4.

Table 4. Annual load simulation results of TN under regulation project model

\begin{tabular}{c|c|c}
\hline Regulation project mode & TN/kg & change rate \\
\hline Farmland changed into forest land & 257.22 & $-11 \%$ \\
Building changed into forest land & 281.14 & $-3 \%$ \\
Farmland changed into grassland & 276.89 & $-4 \%$ \\
Building changed into grassland & 285.65 & $-1 \%$ \\
\hline
\end{tabular}

In Table 4, the nitrogen load of the four regulation modes can be observed, when the farmland was changed into forest land mode, the total nitrogen yield was $257.22 \mathrm{~kg}$, which decreased by $11 \%$. When the building was changed into forest land mode, the total nitrogen yield was $281.14 \mathrm{~kg}$, which decreased by $3 \%$. When the farmland was changed into grassland mode, the total nitrogen yield was $276.89 \mathrm{~kg}$, which decreased by $4 \%$ When the building was changed into grassland mode, the total nitrogen yield was $285.65 \mathrm{~kg}$, which decreased by $1 \%$. It can be concluded that the total nitrogen output is the least when the farmland is transformed into forest land, while the total nitrogen output is the most when the building is transformed into grassland.

Table 5 presents the nitrogen load in the four regulation modes, when the farmland was changed into forest land mode, the total phosphorus output was the least, $27.79 \mathrm{~kg}$, which decreased by $24 \%$. When the building was changed into forest land mode, the total phosphorus output was $32.99 \mathrm{~kg}$, which reduced by $10 \%$. When the farmland was changed into grassland mode, the total phosphorus output was $29.62 \mathrm{~kg}$, which reduced by $19 \%$. When the building was changed into forest land, the total phosphorus output was $34.48 \mathrm{~kg}$, which reduced by $6 \%$.

Table 5. Annual load simulation results of TP under regulation project model

\begin{tabular}{c|c|c}
\hline Regulation project mode & TP/kg & Change rate \\
\hline Farmland changed into forest land & 27.79 & $-24 \%$ \\
Building changed into forest land & 32.99 & $-10 \%$ \\
Farmland changed into grassland & 29.62 & $-19 \%$ \\
Building changed into grassland & 34.48 & $-6 \%$ \\
\hline
\end{tabular}

According to the results, if a series of non-point source pollution control measures are not implemented, the non-point source pollution will be further increased. Therefore, in order to predict the increasing trend of non-point source pollution, it is necessary to strengthen planting and grass planting, return farmland to forest, reduce the application of fertilizers and increase wetlands. 


\section{Discussion and conclusion}

Four typical sub-watersheds in the Caohai Jiahaizi river watershed, Dongshan river watershed, Baima river watershed and Zhonghe river watershed were selected for SWAT simulation analysis under the four regulation projects. The results showed that the non-point source pollution was less under the four regulation projects, among which the non-point source pollution was less under the conversion of farmland into forest land. Combined with the current situation of land use in the Caohai river watershed, reasonable fertilization should be adopted to reduce non-point source pollution, and a series of greening measures should be adopted, such as planting a variety of shrubs, reducing soil erosion, reducing pollutants into water and increasing wetlands. These treatment schemes have a good effect on controlling non-point source pollution. In order to guarantee the good water quality and improve the water and soil conservation capacity of the Caohai watershed, non-point source pollution should be effectively controlled and the quality of life of the people should be improved.

In order to maintain the water environment health and promote the sustainable development of ecology, economy and society in the Caohai watershed, we should continue to carry out comprehensive water environment improvement in Caohai watershed and invest sufficient manpower and financial resources. Therefore, it is suggested that: first, a mechanism should be established to guarantee the funds for comprehensive remediation of the Caohai watershed to ensure the continuous investment of funds. Second, the mechanism of ecological compensation and protection for water environment in the Caohai river watershed should be established to reverse the long-term lack of systematic planning and protection and reduce the economic burden of ecological construction. Third, it is necessary to establish a mechanism of supervision and inspection for comprehensive regulation of the Caohai river watershed, make the task clear, fulfil responsibility, unify the local departments in thinking, and put watershed management into practice as the responsibility. Fourth, exploring the technical methods according to local conditions and introducing practical and applicable water ecological restoration methods are essential. Fifth, it is necessary to establish a monitoring, dispatching, early warning platform and information sharing mechanism, along with a multi-sector monitoring system, improve the level of comprehensive decision-making management, and achieve sustainable development of the grassland watershed.

Acknowledgements. This work was supported by the Major Project of Guizhou Province (Qian Ke He Major Project Zi [2016]3022-06), the Application Foundation Major Project of Guizhou Province (Qian Ke He JZ Zi [2014] 200211), the Construction Program of Biology First-class Discipline in Guizhou (GNYL [2017] 009), the Key Discipline Construction Project of Ecology in Guizhou Province (Guizhou Degree ZDXK[2016]7)

\section{REFERENCES}

[1] Dechmi, F., Burguete, J., Skhiri, A. (2012): SWAT application in intensive irrigation systems: Modeling, calibration and validation. - Journal of Hydrology 470/471: 227-238. 
[2] Fan, L., Zhang, D., Duan, H., Yang, H., Yang, P., Luo, B. (2015): Study on the prevention and control measures of agricultural non-point source pollution in China. Environmental Science and Management 40(11): 85-87.

[3] Ficklin, D. L., Luo, Y., Luedeling, E. et al. (2009): Climate change sensitivity assessment of a highly agricultural watershed using SWAT. - Journal of Hydrology 374(1-2): 16-29.

[4] Guo, J., Zhang, Z., Wang, S., Strauss, P., Yao, A. (2014): Application of SWAT model to study the impact of land use and climate change on runoff in Chaohe River Basin. Journal of Ecology 34(6): 1559-1567.

[5] Li, C., Hu, Y., Liu, Z. (2013): Research progress of urban non-point source pollution. Journal of Ecology 32(3): 492-500.

[6] Li, S., Wei, H., Liu, Y., Ma, W., Gu, Y., Peng, Y., Li, C. (2017): Runoff simulation of Qingshui River Basin in Ningxia under climate and land use change. - Journal of Ecology 37(4): 1252-1260.

[7] Luo, Q., Ren, L., Peng, W. (2014): Non-point source nitrogen and phosphorus load simulation analysis in Liaoning Taizi River Basin. - China Environmental Science 34(1): 178-186.

[8] Luo, Z., Liu, W., Li, Z., Li, X. (2017): Nest site selection of Tachybaptus ruficollis in Caohai National Nature Reserve, Guizhou, China Sichuan. - Journal of Zoology 36(2): 174-180.

[9] Rahman, K., Da Silva, A. G., Tejeda, E. M., Gobiet, A., Beniston, M., Lehmann, A. (2015): An independent and combined effect analysis of land use and climate change in the upper Rhone River watershed, Switzerland. - Applied Geography 63: 264-272.

[10] Sakaguchia, A., Eguchia, S., Katob, T. et al. (2014): Development and evaluation of a paddy module for improving hydrological simulation in SWAT. - Agricultural Water Management 137: 116-122.

[11] Strauch, M., Volk, M. (2013): SWAT plant growth modification for improved modeling of perennial vegetation in the tropics. - Ecological Modelling 269: 98-112.

[12] Wu, Y. P., Liu, S. G., Chen, J. (2012): Urbanization eases water crisis in China. Environmental Development 2: 141-144.

[13] Xia, P. H., Kong, X. L., Yu, L. F. (2016): Effects of land-use and landscape pattern on nitrogen and phosphorus exports in Caohai wetland watershed. - Acta Scientiae Circumstantiae 36(8): 2983-2989.

[14] Yang, L., Gao, H. (2016): Research progress of non-point source pollution models at home and abroad. - Resource Conservation and Environmental Protection 23(5): 151155.

[15] Yuan, Y., Zhang, Z., Meng, J. (2015): Impact of land use and climate change on runoff in Liuxi River Basin based on SWAT model. - Journal of Applied Ecology 26(4): 989-998.

[16] Zhang, L., Karthikeyan, R., Bai, Z. K., Srinivasan, R. (2017): Analysis of streamflow responses to climate variability and land use change in the Loess Plateau Region of China. - Catena 154: 1-11.

[17] Zhao, A.-Z., Zhao, Y.-L., Liu, X., Zhu, X., Pan, Y., Chen, Y. (2016): Study on the impacts of climate change and human activities on blue and green water in the Weihe River Basin. - Geographical Science 36(4): 571-579.

[18] Zheng, J.-N., Xia, P.-H., Lin, T., Zhou, Y. (2013): The contents and distributive characteristics of nitrogen and phosphorus in farmland ditches of the suburban mixed area near to Caohai Natural Reserve, Guizhou. - Journal of Mountain Agriculture and Biology. 